\title{
Türkiye'de eski ve yeni üretim bölgelerinde fındık yetiştiriciliği yapan işletmelerin tarımsal üretim açısından karşılaştırmalı analizi
}

\author{
Derya ÖZTÜRK (iD) 1 , Ali İSLAM ${ }^{(D 2}$ \\ 1Ordu Üniversitesi Ünye İktisadi ve İdari Bilimler Fakültesi, İşletme Bölümü Ordu \\ 20rdu Üniversitesi, Ziraat Fakültesi, Bahçe Bitkileri Bölümü, Ordu
}

Alınıș tarihi: 28 Aralık 2018, Kabul tarihi: 13 Şubat 2019

Sorumlu yazar: Derya ÖZTÜRK, e-posta: deryaozturk@odu.edu.tr

\section{$\ddot{0} \mathbf{z}$}

$\mathrm{Bu}$ araştırmanın amacı, dünya fındık üretiminde ilk sırada yer alan Türkiye'de, fındık üretiminin yapıldığı eski ve yeni üretim bölgelerindeki fındık işletmelerini tarımsal üretim açısından karşılaştırmalı analiz etmektir. Araştırmanın verileri, eski üretim bölgesinden 183 ve yeni üretim bölgesinden 92 findık işletmesinden anket yoluyla elde edilmiştir. İki üretim bölgesindeki işletmelerin tarımsal üretim arasındaki farklılı̆̆ Ki-kare analizi ile ortaya konulmuştur. Elde edilen sonuçlara göre, işletme yöneticisinin öğrenim durumunun, ikamet yerinin, fındık dikim yaşının, hasat şeklinin, hasatta makine kullanımının ve sulama durumunun findık üretim bölgelerine göre farklılık gösterdiği tespit edilmiştir. Eski üretim bölgesindeki işletme yöneticilerinin \%63.9'u ilköğretim mezunu ve \%49.2'si köylerde ikamet ederken, yeni üretim bölgesinde bu oranlar \%82.6 ve \%78.3 tür. Eski üretim bölgesindeki işletmelerin \%54.1'inin findık dikim yașının 31-60 yıl aralığında olduğu, \%33.9'unun silkme suretiyle yerden toplayarak fındık hasadını yaptı̆̆ı, \%1.1'inin hasatta makine kullandığı ve sadece \%1.6'sının fındık bahçelerinde sulama yaptığı saptanmıştır. Yeni üretim bölgesindeki işletmelerin ise \%64.1'inin findık bahçesi dikim yaşının 0-30 yıl aralığında değiştiği, \%39.1'inin yerden toplayarak findık hasadını yaptıkları, \%5.4'ünün hasatta makine kullandıkları ve \%10.9'unun findık bahçelerinde sulama yaptıkları tespit edilmiştir. Araştırma sonuçları bütün olarak değerlendirildiğinde yeni üretim bölgesindeki bahçelerde kültürel bakımın ve mekanizasyon uygulamalarının eski bölgeye göre yapılma eğiliminin yüksek olduğu ortaya konulmaktadır.
Anahtar kelimeler: Fındık, tarımsal üretim, işletme, Corylus

Comparative analysis of hazelnut growing companies in old and new production zones in Turkey
Abstract
Turkey is the world's largest hazelnut producer. The aim of this study is to comparatively analyze hazelnut growing companies in old and new production zones in Turkey. This study consisted of 183 hazelnut companies operating in old zones and 92 hazelnut companies operating in new ones. Data were collected using a survey tool. Two groups were compared using chi-square test. Results show that managers' education levels and places of residence, hazelnut plantation age, harvest type, use of machinery in harvesting and irrigation vary from zone to zone. $63.9 \%$ of managers of companies operating in old production zones have a primary school degree and $49.2 \%$ live in villages while they are $82.6 \%$ and $78.3 \%$ in new production zones, respectively. Of companies operating in old production zones, $54.1 \%$ have been producing hazelnuts for 31 to 60 years, $33.9 \%$ shake the trees and pick the nuts off the ground, 1.1\% use machinery in harvesting and only $1.6 \%$ irrigate the hazelnut groves. Of companies operating in new production zones, $64.1 \%$ have been producing hazelnuts for less than 1 year to 30 years, 39.1\% shake the trees and pick the nuts off the ground, $5.4 \%$ use machinery in harvesting and $10.9 \%$ irrigate the hazelnut groves. Results indicate that cultural maintenance and mechanization practices 
are more likely to be performed in new production zones than in the old ones.

Key words: Hazelnut, agricultural production, company, Corylus

\section{Giriş}

Tarım sektörü, ülke ekonomisinin gelişmesinde stratejik öneme sahip bir sektör konumundadır. Tarımsal yapıdaki bir ekonomiden sanayileşmiş bir ekonomiye geçilirken, tarım sektörü başlıca dört fonksiyonu yerine getirir. Bunlar; gıda maddeleri talebinin karşılanması, döviz gelirlerine katkıda bulunmak üzere üretim fazlasının oluşturulması, kalkınma için gerekli sermaye ve işgücü transferinin sağlanması ve talep potansiyeli oluşturarak sanayi malları üretiminin hızlandırılmasıdır (Cinemre ve Kılıç, 2015). Son yıllarda meydana gelen teknolojik gelişmeler, diğer sektörlerde olduğu gibi tarım sektöründe de kullanılan üretim tekniklerinde büyük değişmelere yol açmıştır. $\mathrm{Bu}$ durumda gelişen teknolojiye ayak uydurmak için, tarım işletmeleri de sadece kendi ailesinin üretimini sağlayan içe dönük üretim anlayışı yerine verim, kalite ve kârlılığı esas alan bir üretim anlayışıyla çalışmak zorundadır.

Türkiye, fındık kültürünün anavatan bölgeleri arasında olup büyük bir zenginliğe sahiptir. $\mathrm{Bu}$ zenginlik üretimde çok sayıda çeşitleri ortaya çıkarmıştır. Bunun sonucu olarak dünya fındık üretimindeki yerimiz uzun yıllar ilk sırada olarak süregelmektedir (İslam, 2018). Türkiye'de fındık ihracatı ise, tarım ürünleri ihracatı içerisinde daima ilk sıralarda yer almakta ve birçok tarım işletmesi için büyük ölçüde tek geçim kaynağı durumundadır. Fiskobirlik tarafından fındığa alım garantisi verilmesi ve bazı yıllar uygulanan yüksek destekleme alım fiyatlarından dolayı, başlangıçta Doğu Karadeniz illerinde üretime alınan fındık, zamanla Batı Karadeniz'e doğru genişleyerek hızlı bir gelişme göstermiştir (Kılıç, 2004). Ülkemizde fındık eski ve yeni bölge olarak adlandırılan kuzeyde yetiştirilmektedir. Eski bölge Doğu Karadeniz bölgesi olup Ordu, Giresun, Trabzon, Rize, Artvin illerini kapsamaktadır. Yeni bölge ise orta ve batı Karadeniz bölgesi olup ağırlıklı olarak Samsun, Sinop, Düzce, Sakarya, Zonguldak, Kocaeli illerini kapsar (İslam, 2018). Dünya fındık üretim alanının 2017 yılı itibariyle \%75'i, üretim miktarının ise \%67.67'si Türkiye tarafından karşılanmaktadır (Anonim, 2018a). 2017 yılı itibariyle, Türkiye fındık üretim miktarının \%52.5'ini eski üretim bölgesi, \%47.1'ini yeni üretim bölgesi karşllarken, findık üretim alanının \%59.7'sini eski üretim bölgesi, \%39.9'unu yeni üretim bölgesi oluşturmaktadır (Anonim, 2018b). Türkiye'de findık, yaratmış olduğu katma değer ve ihracat geliriyle ekonomiye önemli katkılar sağlamaktadır. Bitkisel ürün ihracatı içinde önemli bir paya sahip olan findık; hububat, bakliyat, yağlı tohumlar ve mamulleri ile yaş meyve ve sebze grubundan sonra yaklaşı \%12'lik payla üçüncü sırada yer almaktadır (Anonim, 2018c). Türkiye'de konvansiyonel fındık üretiminin yanı sıra organik findık üretimi her iki bölgede önemli bir değer arz etmektedir (Öztürk ve İslam, 2014).

Türkiye dışında diğer fındık üreticisi ülkelerin son yıllarda üretimlerini artırmaları, Türkiye'nin üretim ve ihracattaki avantajını giderek düşürmektedir. $\mathrm{Bu}$ bakımdan Türkiye, findık üretim maliyetini düşürmek ve kaliteyi yüksek seviyede tutmak zorundadır. Fındıkta üretim maliyetini düşürmek için verimin artırılması yanında, girdilerin etkin kullanımının da sağlanması gerekmektedir. Ayrıca, işleme sanayisine uygun çeşit seçimi ve bakım şartlarının da iyileştirilmesi büyük önem taşımaktadır (Kılıç ve Demir, 2004). Tarım sektöründe verimlilik, toprak yapısı ve iklim koşulları gibi kontrol edilemeyen unsurların yanı sıra gübreleme, sulama, ilaçlama, hastalıkzararlılarla mücadele gibi faktörlere de bağlıdır. Tarımsal işletmelerde ürün veriminin artırılması, işletme yöneticilerinin tarımsal üretim teknolojileri ve yetiştiricilikle ilgili bilimsel bilgileri öğrenerek tekniğine uygun üretim yapmalarıyla doğrudan ilișkilidir. Bu doğrultuda çalışmada, Türkiye'de eski ve yeni üretim bölgelerindeki fındık yetiştiriciliği yapan işletmelerin tarımsal üretim açısından farklılıklarının ortaya konulması ve bu farklılıklara ilişkin çözüm önerilerinin geliştirilmesi amaçlanmıştır.

Türkiye'de yeni ve eski üretim bölgelerindeki fındık işletmelerinin sosyo-ekonomik özellikleriyle ilgili çok sayıda çalışma bulunmaktadır. Bu çalışmalarda; fındık bahçelerinin büyüklüğü, parçalılık durumları, nüfus ve işgücü yapıları, fındık çeşitleri, bahçenin dikim şekli, uyguladıkları üretim teknikleri ve sermaye yapıları, gelir ve gider durumları ele alınmıştır (İslam, 1997; Kılıç, 1997; Kızıltan ve Yalçın, 2010; Öztürk ve Akçay, 2011; Öztürk ve Kasko Arıcı, 2017). Ancak, Türkiye'de findık üretim alanlarını eski ve yeni üretim bölgeleri şeklinde gruplandırmak suretiyle findık yetiştiriciliğinin yapıldığı işletmeleri tarımsal üretim açısından karşılaştırmalı olarak ele alan herhangi bir çalışmaya 
rastlanmamıș olup, bu açıdan çalıșma orijinallik taşımaktadır. Bu yönüyle çalışmanın, literatürdeki bu boşluğu dolduracağı ve konu ile ilgili yapılacak çalışmalara önemli katkılar sağlayacağı düşünülmektedir.

\section{Materyal ve Yöntem}

\section{Materyal}

Araştırmanın evrenini, eski üretim bölgesinde (Trabzon, Giresun, Ordu, Rize, Gümüşhane, Artvin) ve yeni üretim bölgesinde (Samsun, Sinop, Düzce, Bolu, Bartın, Sakarya, Kastamonu, Zonguldak, Kocaeli, Tokat) fındık yetiștiriciliği yapan tüm işletmeler olușturmaktadır. Araștırmanın örneklemini ise, eski üretim bölgesinde 183 ve yeni üretim bölgesinde 92 findık işletmesinden kolayda örnekleme yoluyla seçilen toplam 275 işletme olușturmaktadır.

\section{Yöntem}

Araştırmada evrenin tamamına ulașmak emek, zaman ve maliyet gibi önemli kısıtlar açısından mümkün olmadığından, tesadüfi olmayan örnekleme yöntemlerinden kolayda örnekleme yönteminin kullanılması uygun görülmüştür. $\mathrm{Bu}$ araştırmada kolayda örnekleme yönteminde veriler, ana kütleden en kolay, hızlı ve ekonomik şekilde toplandığından (Aaker vd., 2007) tercih edilmiştir. Anket uygulaması, 2017-2018 üretim döneminde gerçekleştirilmiştir. Araştırmada veri toplama yöntemi olarak yüz yüze görüşme, veri toplama aracı olarak ise araştırma değişkenlerini ölçmeye yönelik olarak hazırlanmış anket formları kullanılmıştır. Anket formu; işletme yöneticilerinin demografik özellikleri ve fındık yetiştiriciliğine ilişskin tarımsal üretim ve uygulama konusundaki bilgilerini ölçmeye yönelik hazırlanan toplam 16 sorudan oluşan iki bölümü kapsamaktadır. Frekans değerleri ile belirlenen değișkenler arasındaki ilișkileri incelemek amacıyla, çapraz tablolar oluşturulmuş ve tablolarda bağımsızlık kontrolü ki-kare testi $\left(\chi^{2}\right)$ ile yapılmıştır. Ki-kare testlerinde; beklenen frekanslar 5'in altında gerçekleştiği için Likelihood Ratio kikare değeri (LR $\left.\chi^{2}\right)$ hesaplanmıştır. Ki-kare testlerinde ve sonuçlarının yorumlanmasında önemlilik düzeyi $(\alpha) \% 5$ olarak dikkate alınmıştır. Tüm hesaplamalar SPSS v24 (IBM Inc., Chicago, IL, USA) istatistik paket programıyla yapılmıştır.

\section{Araştırma Bulguları}

Araştırmada anket yapılan findık işletmelerinin $\% 66.5$ 'i eski üretim bölgesinde, \%33.5'i yeni üretim bölgesindedir. Eski üretim bölgesindeki işletme yöneticilerinin \%16.4'ü 23-40 yaş, \%54.6'sı 41-60 yaş, $\% 29^{\prime}$ u ise 60 yaş üzerinde bulunmaktadır. Yeni üretim bölgesindeki işletme yöneticilerinin ise \%18.5'i 23-40 yaş, \%59.8'i 41-60 yaș, \%21.7'si ise 60 yaş üzerindedir. Eski üretim bölgesindeki işletme yöneticilerinin $\quad \% 63.9^{\prime} \mathrm{u} \quad$ ilköğretim, \%19.1'i ortaöğretim ve $\% 16.9^{\prime} u$ ise yükseköğretim düzeyinde eğitim seviyesine sahiptir. Yeni üretim bölgesindeki işletme yöneticilerinin ise \%82.6'sı ilköğretim, \%10.9'u ortaöğretim ve \%6.5'i ise yükseköğretim düzeyinde eğitim seviyesine sahiptir. Eski üretim bölgesindeki yöneticilerin \%49.2'si köylerde, \%48.6'sı ilçe veya illerde, \%2.2'si ise findık bahçelerinin bulunduğu ilin dișında ikamet etmektedir. Yeni üretim bölgesindeki yöneticilerin ise \%78.3'ü köylerde, \%19.6'sı ilçe veya illerde, \%2.2'si ise il dışında ikamet etmektedir. Üreticilerin köyde yaşama ve eğitim seviyeleri dikkate alındığında yeni üretim bölgesindeki üreticilerin üretim ve çiftçiliğe daha yatkın olduğu söylenebilir.

Anket yapılan findık işletmelerinin tarımsal üretimine ilişkin durumu Çizelge 1'de verilmiștir.

Eski üretim bölgesindeki işletmelerin \%54.1'inin fındık bahçesi dikim yaşının 31-60 yaş, yeni üretim bölgesindeki işletmelerin \%64.1'inin ise 0-30 yaş aralığında olduğu tespit edilmiștir. Eski üretim bölgesindeki işletmelerin findık bahçelerinin \%33.5'ini Tombul, \%20.4'ünü Çakıldak, \%15.5'ini Sivri, \%14'ünü Palaz, \%5.3'ünü Foşa, \%4.1'ini Kara, \%1.7'sini Kalınkara, \%1.7'sini yöresel çeşitler, \%1.7'sini İncekara, \%1.2'sini Kuş, \%0.6'sını Mincane ve $\% 0.3$ 'ünü Yuvarlak Badem ve Yassı Badem çeșitleri oluşturmaktadır. Yeni üretim bölgesindeki işletmelerde ise findık çeşitleri; \%30.8'i Çakıldak, \%16.3'ü Foşa, \%22.1'i Tombul, \%4'ü Sivri, \%10.2'si Palaz, \%8.6'ı Mincane, \%4.3'ü Kalınkara ve \%3.7'si Kara șeklindedir. Eski üretim bölgesindeki işletmelerin \%59.6'sı ve yeni üretim bölgesindeki işletmelerin \%62'si findığın hasadını daldan yapmaktadır. Hem daldan hem de yerden findık hasadını yapan işletmelerin oranı; eski üretim bölgesinde \%6.6 ve yeni üretim bölgesinde \%14.1'dir. Her iki üretim bölgesinde de findık hasadının genellikle insan gücüyle yapıldığı, makineli hasat yapan ișletmelerin oranının oldukça düșük olduğu görülmektedir. $\mathrm{Bu}$ oran eski üretim bölgesinde \%1.1 ve yeni üretim bölgesinde \%5.1'dir. Fındık hasadı öncesi dip sürgünü temizliği yaptıranların oranı; eski üretim bölgesindeki işletmelerde \%79.2 iken, yeni üretim bölgesindeki 
işletmelerde \%72.8'dir. Eski üretim bölgesindeki işletmelerin \%20.2'si ve yeni üretim bölgesindeki işletmelerin \%21.7'si en çok 3 yılda bir findık bahçelerine toprak analizi yaptırdıklarını ifade etmişlerdir. Hastalık ve zararlılarla mücadele edenlerin oranı ise; eski üretim bölgesindeki işletmelerde \%54.6 ve yeni üretim bölgesindeki işletmelerde \%59.8'dir. Eski üretim bölgesindeki işletmelerin \%52.5'i fındık kurdu, \%27.5'i külleme, \%13.3'ü dalkıran, \%3.3'ü kozalak akarı, \%1.7'si filiz güvesi ve \%1.7'si kokarca gibi hastalık ve zararlılarla mücadele etmektedir. Yeni üretim bölgesindeki ișletmelerin ise \%46.7'si külleme, \%40'ı fındık kurdu, \%5'i Amerikan beyaz kelebeği, \%3.3'ü dalkıran, \%3.3'ü fındık kurdu ve \%1.7'si kozalak akarı gibi hastalık ve zararlılarla mücadele etmektedir. Her iki üretim bölgesinde de işletmelerin büyük çoğunluğu fındık bahçelerini sulamadığını belirtirken, fındık bahçelerini sulayanların oranı; eski üretim bölgesindeki işletmelerde \%1.6 ve yeni üretim bölgesindeki işletmelerde \%10.9 şeklinde gerçekleşmiştir. Her iki üretim bölgesinde de yine işletmelerin büyük çoğunluğu findık yetiştiriciliği ile ilgili konularda Tarım İl/İlçe Müdürlüklerinden destek almaktadır.

Araştırmada, işletme yöneticilerinin yaş, eğitim, ikamet yeri, fındık bahçesi dikim yaşı, hasat şekli, makineli hasat durumu, en çok 3 yılda bir toprak analizi yaptırma, hastalık ve zararlılarla mücadele, hasat öncesi dip sürgünü temizliği yaptırma, sulama durumu ve hangi kurumdan destek aldığı gibi değişkenler ile findık üretim bölgeleri arasındaki ilişkileri inceleyebilmek amacıyla çapraz tablolar oluşturulmuş ve çapraz tablolarda bağımsızlık kontrolü ki-kare testi (Chi-Square test, $\chi^{2}$ ) ile yapılmıştır.

Fındık işletmelerindeki yöneticilerin yaşı üretim bölgelerine göre değişim göstermemektedir ( $p>0.05$; Çizelge 2).

Çizelge 1. Fındık işletmelerinin tarımsal üretim durumu

\begin{tabular}{|c|c|c|c|c|c|}
\hline & & \multicolumn{2}{|c|}{ Eski Üretim Bölgesi } & \multicolumn{2}{|c|}{ Yeni Üretim Bölgesi } \\
\hline & & $\mathrm{n}$ & $\%$ & $\mathrm{n}$ & $\%$ \\
\hline \multirow{4}{*}{ Bahçe dikim yaşı } & $0-30$ & 57 & 31.1 & 59 & 64.1 \\
\hline & $31-60$ & 99 & 54.1 & 32 & 34.8 \\
\hline & $61+$ & 27 & 14.8 & 1 & 1.1 \\
\hline & Toplam & 183 & 100.0 & 92 & 100.0 \\
\hline \multirow{4}{*}{ Hasat şekli } & Daldan & 109 & 59.6 & 57 & 62.0 \\
\hline & Yerden & 62 & 33.9 & 22 & 23.9 \\
\hline & Her ikisi & 12 & 6.6 & 13 & 14.1 \\
\hline & Toplam & 183 & 100.0 & 92 & 100.0 \\
\hline \multirow{3}{*}{ Makineli hasat yapma } & Evet & 2 & 1.1 & 5 & 5.4 \\
\hline & Hayır & 181 & 98.9 & 87 & 94.6 \\
\hline & Toplam & 183 & 100.0 & 92 & 100.0 \\
\hline \multirow{3}{*}{$\begin{array}{l}\text { Hasat öncesi dip sürgünü } \\
\text { temizliği yaptırma }\end{array}$} & Evet & 145 & 79.2 & 67 & 72.8 \\
\hline & Hayır & 38 & 20.8 & 25 & 27.2 \\
\hline & Toplam & 183 & 100.0 & 92 & 100.0 \\
\hline \multirow{3}{*}{$\begin{array}{l}\text { En çok } 3 \text { yılda bir toprak analizi } \\
\text { yaptırma }\end{array}$} & Evet & 37 & 20.2 & 20 & 21.7 \\
\hline & Hayır & 146 & 79.8 & 72 & 78.3 \\
\hline & Toplam & 183 & 100.0 & 92 & 100.0 \\
\hline \multirow{3}{*}{$\begin{array}{l}\text { Hastalık ve zararlılarla mücadele } \\
\text { yapma }\end{array}$} & Evet & 100 & 54.6 & 55 & 59.8 \\
\hline & Hayır & 83 & 45.4 & 37 & 40.2 \\
\hline & Toplam & 183 & 100.0 & 92 & 100.0 \\
\hline \multirow{3}{*}{ Sulama yapma } & Evet & 3 & 1.6 & 10 & 10.9 \\
\hline & Hayır & 180 & 98.4 & 82 & 89.1 \\
\hline & Toplam & 183 & 100.0 & 92 & 100.0 \\
\hline \multirow{6}{*}{ Destek alınan kurumlar } & Tarım İl/İlçe Müdürlüğü & 147 & 80.3 & 74 & 80.4 \\
\hline & Üniversite & 3 & 1.6 & 0 & 0.0 \\
\hline & Ziraat Odası & 2 & 1.1 & 3 & 3.3 \\
\hline & $\begin{array}{l}\text { Tarım İl/ilçe Müdürlüğü ve } \\
\text { Ziraat Odası }\end{array}$ & 10 & 5.5 & 4 & 4.3 \\
\hline & Hiçbiri & 21 & 11.5 & 11 & 12.0 \\
\hline & Toplam & 183 & 100.0 & 92 & 100.0 \\
\hline
\end{tabular}


Çizelge 2. İşletme yöneticilerinin yaşının üretim bölgelerine göre dağılımı ve karşılaştırma sonuçları

\begin{tabular}{|c|c|c|c|c|c|}
\hline & & & \multicolumn{3}{|c|}{ Üretim Bölgeleri } \\
\hline & & & Eski üretim bölgesi & Yeni üretim bölgesi & Toplam \\
\hline \multirow{6}{*}{$\begin{array}{l}\text { İşletme yöneticisinin } \\
\text { yaşı }\end{array}$} & \multirow{2}{*}{$23-40$} & $\mathrm{n}$ & 30 & 17 & 47 \\
\hline & & $\%$ & 16.4 & 18.5 & 17.1 \\
\hline & \multirow{2}{*}{$41-60$} & $\mathrm{n}$ & 100 & 55 & 155 \\
\hline & & $\%$ & 54.6 & 59.8 & 56.4 \\
\hline & \multirow{2}{*}{61 ve üzeri } & $\mathrm{n}$ & 53 & 20 & 73 \\
\hline & & $\%$ & 29.0 & 21.7 & 26.5 \\
\hline \multirow{2}{*}{\multicolumn{2}{|c|}{ Toplam }} & $\mathrm{n}$ & 183 & 92 & 275 \\
\hline & & $\%$ & 100.0 & 100.0 & 100.0 \\
\hline \multicolumn{3}{|c|}{ P-Değeri } & $0.431^{\text {ÖD }}\left(\mathrm{LR} \chi^{2}=1.6\right.$ & & \\
\hline
\end{tabular}

öD, istatistik olarak önemli değildir ( $\mathrm{p}>0.05)$.

Çizelge 3. İşletme yöneticilerinin eğitiminin üretim bölgelerine göre dağılımı ve karşılaştırma sonuçları

\begin{tabular}{|c|c|c|c|c|c|}
\hline & & & \multicolumn{3}{|c|}{ Üretim Bölgeleri } \\
\hline & & & Eski üretim bölgesi & Yeni üretim bölgesi & Toplam \\
\hline \multirow{6}{*}{$\begin{array}{l}\text { İşletme yöneticisinin } \\
\text { eğitimi }\end{array}$} & \multirow{2}{*}{ İlköğretim } & $\mathrm{n}$ & 117 & 76 & 193 \\
\hline & & $\%$ & 63.9 & 82.6 & 70.2 \\
\hline & \multirow{2}{*}{ Ortaöğretim } & $\mathrm{n}$ & 35 & 10 & 45 \\
\hline & & $\%$ & 19.1 & 10.9 & 16.4 \\
\hline & \multirow{2}{*}{ Yükseköğretim } & $\mathrm{n}$ & 31 & 6 & 37 \\
\hline & & $\%$ & 16.9 & 6.5 & 13.5 \\
\hline \multirow{2}{*}{\multicolumn{2}{|c|}{ Toplam }} & $\mathrm{n}$ & 183 & 92 & 275 \\
\hline & & $\%$ & 100.0 & 100.0 & 100.0 \\
\hline \multicolumn{3}{|c|}{ P-Değeri } & $0.004^{*}\left(\operatorname{LR} \chi^{2}=11.2\right.$ & & \\
\hline
\end{tabular}

*, istatistik olarak önemlidir $(\mathrm{p}<0.05)$

Çizelge 4. İşletme yöneticilerinin ikamet yerlerinin üretim bölgelerine göre dağılımı ve karşlaştırma sonuçları

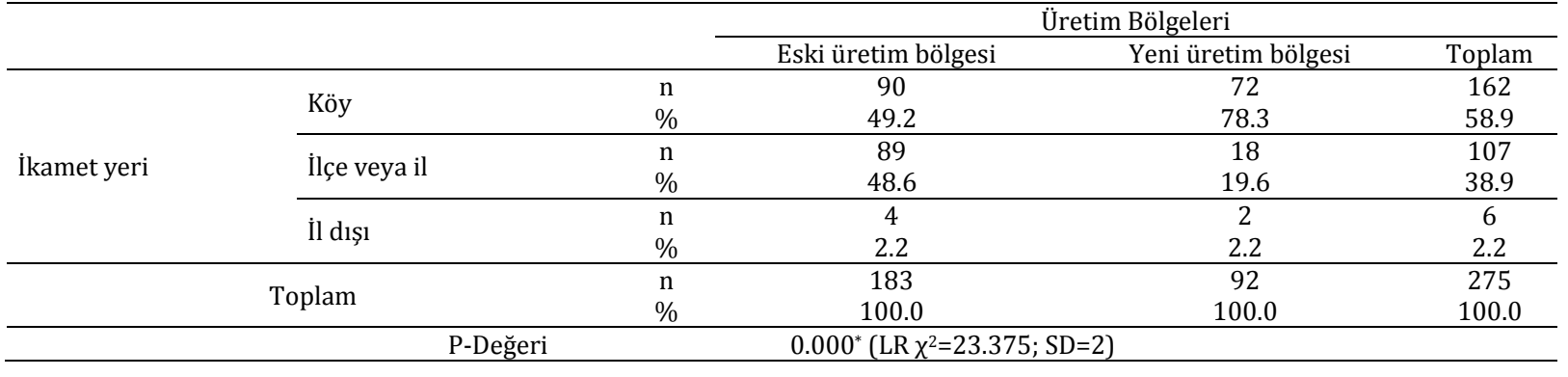

*, istatistik olarak önemlidir $(\mathrm{p}<0.05)$.

Çizelge 3 incelendiğinde, işletme yöneticilerinin eğitim durumunun üretim bölgelerine göre değişim gösterdiği görülmektedir $(\mathrm{p}<0.05)$. Eski üretim bölgesindeki işletme yöneticilerinin \%63.9'u, yeni üretim bölgesindeki işletme yöneticilerinin ise \%82.6'sı ilköğretim düzeyinde eğitim seviyesine sahiptir. İncelenen ișletmelerde yöneticilerin ikamet yerlerinin üretim bölgelerine göre değişim gösterdiği görülmektedir ( $\mathrm{p}<0.05$; Çizelge 4$)$. Eski üretim bölgesindeki yöneticilerin \%49.2'sinin, yeni üretim bölgesindeki yöneticilerin ise \%78.3'ünün köylerde ikamet ettiği tespit edilmiştir. Çizelge 5 incelendiğinde, işletmelerin findık bahçesi dikim yaşlarının üretim bölgelerine göre değişim gösterdiği görülmektedir $(\mathrm{p}<0.05)$. Hasat ş̧ekli bakımından üretim bölgelerine göre değişim görülmemektedir $(p<0.05$; Çizelge 6$)$. Çizelge 7 incelendiğinde, fındık işletmelerinde makineli hasat yapma durumunun üretim bölgelerine göre değișim gösterdiği görülmektedir $\quad(\mathrm{p}<0.05)$. İncelenen işletmelerde findık bahçelerinde toprak analizi yaptırma durumu üretim bölgelerine göre değişim göstermemektedir ( $p>0.05$; Çizelge 8). Samsun ilinde yapılan bir çalışmada, Çarşamba ve Terme ovasında fındık işletmelerinin toprak ve yaprak analizi yaptırma durumlarının ki-kare testi sonucuna göre farklılık gösterdiği tespit edilmiştir. Buna göre; işletmelerin Çarşamba ovasında \%46.87'si ve Terme ovasında ise \%29.79'u analiz yaptırdıkların ve analiz yaptırma sayılarını da işletme başına ortalama 1.03 adet ile 0.79 adet olduğunu belirtmişlerdir (Öztürk ve Kasko Arıcı, 2017). 
Çizelge 5. İşletmelerde fındık bahçesi dikim yaşlarının üretim bölgelerine göre dağılımı ve karşılaştırma sonuçları

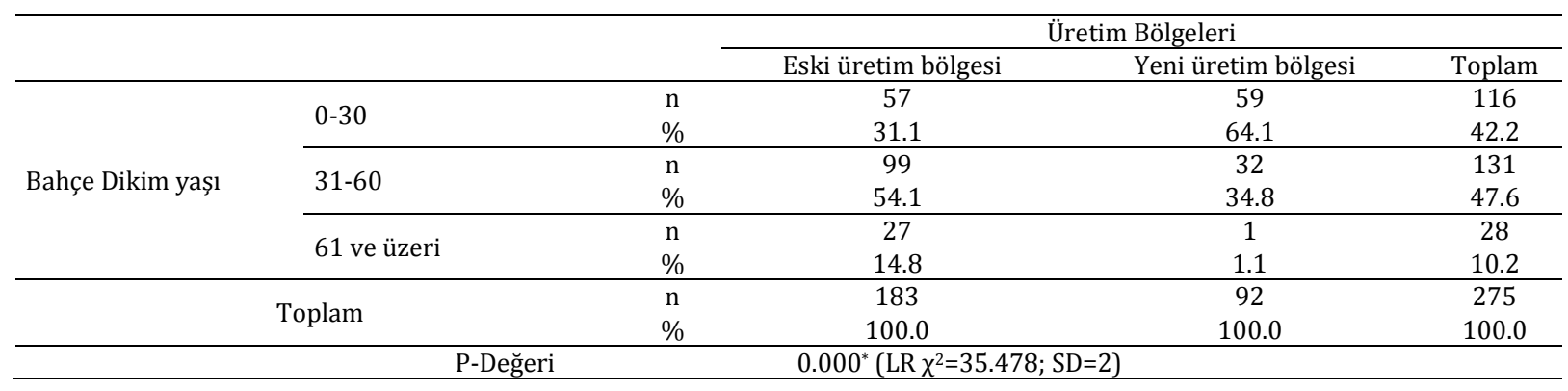

*, istatistik olarak önemlidir $(\mathrm{p}<0.05)$

Çizelge 6. Hasat şekli bakımından üretim bölgelerine göre dağılım ve karşılaştırma sonuçları

\begin{tabular}{|c|c|c|c|c|c|}
\hline & & & \multicolumn{3}{|c|}{ Üretim Bölgeleri } \\
\hline & & & Eski üretim bölgesi & Yeni üretim bölgesi & Toplam \\
\hline \multirow{6}{*}{ Hasat şekli } & \multirow{2}{*}{ Daldan } & $\mathrm{n}$ & 109 & 43 & 152 \\
\hline & & $\%$ & 59.6 & 46.7 & 55.3 \\
\hline & \multirow{2}{*}{ Yerden } & $\mathrm{n}$ & 62 & 36 & 98 \\
\hline & & $\%$ & 33.9 & 39.1 & 35.6 \\
\hline & \multirow{2}{*}{ Her ikisi } & $\mathrm{n}$ & 12 & 13 & 25 \\
\hline & & $\%$ & 6.6 & 14.1 & 9.1 \\
\hline \multirow{3}{*}{\multicolumn{2}{|c|}{ Toplam }} & $\mathrm{n}$ & 183 & 92 & 275 \\
\hline & & $\%$ & 100.0 & 100.0 & 100.0 \\
\hline & & & $0.046^{*}\left(\mathrm{LR} \chi^{2}=6.157\right.$ & & \\
\hline
\end{tabular}

*, istatistik olarak önemlidir $(\mathrm{p}<0.05)$

Çizelge 7. Hasatta makine kullanımının üretim bölgelerine göre dağılımı ve karşılaştırma sonuçları

\begin{tabular}{|c|c|c|c|c|c|}
\hline & & & \multicolumn{3}{|c|}{ Üretim Bölgeleri } \\
\hline & & & Eski üretim bölgesi & Yeni üretim bölgesi & Toplam \\
\hline \multirow{4}{*}{ Makineli hasat yapma } & \multirow{2}{*}{ Evet } & $\mathrm{n}$ & 2 & 5 & 7 \\
\hline & & $\%$ & 1.1 & 5.4 & 2.5 \\
\hline & \multirow{2}{*}{ Hayır } & $\mathrm{n}$ & 181 & 87 & 268 \\
\hline & & $\%$ & 98.9 & 94.6 & 97.5 \\
\hline \multirow{3}{*}{\multicolumn{2}{|c|}{ Toplam }} & $\mathrm{n}$ & 183 & 92 & 275 \\
\hline & & $\%$ & 100.0 & 100.0 & 100.0 \\
\hline & & & $0.031\left(\mathrm{LR} \chi^{2}=4.65\right.$ & & \\
\hline
\end{tabular}

*, istatistik olarak önemlidir $(\mathrm{p}<0.05)$

Çizelge 8. Toprak analizi yaptırma durumunun üretim bölgelerine göre dağılımı ve karşlaştırma sonuçları

\begin{tabular}{|c|c|c|c|c|c|}
\hline & & & \multicolumn{3}{|c|}{ Üretim Bölgeleri } \\
\hline & & & Eski üretim bölgesi & Yeni üretim bölgesi & Toplam \\
\hline \multirow{4}{*}{$\begin{array}{l}\text { En çok } 3 \text { yılda bir toprak analizi } \\
\text { yaptırma }\end{array}$} & \multirow{2}{*}{ Evet } & $\mathrm{n}$ & 37 & 20 & 57 \\
\hline & & $\%$ & 20.2 & 21.7 & 20.7 \\
\hline & \multirow{2}{*}{ Hayır } & $\mathrm{n}$ & 146 & 72 & 218 \\
\hline & & $\%$ & 79.8 & 78.3 & 79.3 \\
\hline \multirow{3}{*}{ Toplam } & & $\mathrm{n}$ & 183 & 92 & 275 \\
\hline & & $\%$ & 100.0 & 100.0 & 100.0 \\
\hline & & & $0.770^{\text {ÖD }}\left(\mathrm{LR} \chi^{2}=0.0\right.$ & & \\
\hline
\end{tabular}

öD, istatistik olarak önemli değildir ( $p>0.05)$.

Çizelge 9 incelendiğinde, işletmelerde hastalık ve zararlılarla mücadele yapma durumunun üretim bölgelerine göre değişim göstermediği görülmektedir $(\mathrm{p}>0.05)$. Ancak yeni üretim bölgesinde bu oran daha yüksektir. İşletmelerde fındık hasadı öncesi dip sürgünü temizliği yaptırma durumunun üretim bölgelerine göre değişim göstermediği tespit edilmiştir ( $\mathrm{p}>0.05$; Çizelge 10). İncelenen işletmelerde findık bahçelerinde sulama yapma durumunun üretim bölgelerine göre değişim gösterdiği görülmektedir ( $\mathrm{p}<0.05$; Çizelge 11). Buna göre; eski üretim bölgesindeki işletmelerin \%1.6'sının, yeni üretim bölgesindeki işletmelerin ise \%10.9'unun findık bahçelerinde sulama yaptığı 
tespit edilmiştir. İşletmelerin fındık yetiştiriciliği ile bölgelerine göre değişim göstermediği tespit ilgili konularda destek aldıkları kurumların üretim edilmiştir ( $p>0.05$; Çizelge 12).

Çizelge 9. Hastalık ve zararlılarla mücadele yapılmasının üretim bölgelerine göre dağılımı ve karşılaştırma sonuçları

\begin{tabular}{|c|c|c|c|c|c|}
\hline & & & \multicolumn{3}{|c|}{ Üretim Bölgeleri } \\
\hline & & & Eski üretim bölgesi & Yeni üretim bölgesi & Toplam \\
\hline \multirow{4}{*}{$\begin{array}{l}\text { Hastalık ve zararlılarla mücadele } \\
\text { yapma }\end{array}$} & \multirow{2}{*}{ Evet } & $\mathrm{n}$ & 100 & 55 & 155 \\
\hline & & $\%$ & 54.6 & 59.8 & 56.4 \\
\hline & \multirow{2}{*}{ Hayır } & $\mathrm{n}$ & 83 & 37 & 120 \\
\hline & & $\%$ & 45.4 & 40.2 & 43.6 \\
\hline \multirow{3}{*}{ Toplam } & & $\mathrm{n}$ & 183 & 92 & 275 \\
\hline & & $\%$ & 100.0 & 100.0 & 100.0 \\
\hline & P-Değeri & & $0.417^{\mathrm{O} D}\left(\mathrm{LR} \chi^{2}=0.6\right.$ & & \\
\hline
\end{tabular}

öD, istatistik olarak önemli değildir ( $p>0.05)$.

Çizelge 10. Dip sürgünü temizliğinin üretim bölgelerine göre dağılımı ve karşılaştırma sonuçları

\begin{tabular}{|c|c|c|c|c|c|}
\hline & & & \multicolumn{3}{|c|}{ Üretim Bölgeleri } \\
\hline & & & Eski üretim bölgesi & Yeni üretim bölgesi & Toplam \\
\hline \multirow{4}{*}{$\begin{array}{l}\text { Hasat öncesi dip sürgünü } \\
\text { temizliği yaptırma }\end{array}$} & \multirow{2}{*}{ Evet } & $\mathrm{n}$ & 145 & 67 & 212 \\
\hline & & $\%$ & 79.2 & 72.8 & 77.1 \\
\hline & \multirow{2}{*}{ Hayır } & $\mathrm{n}$ & 38 & 25 & 63 \\
\hline & & $\%$ & 20.8 & 27.2 & 22.9 \\
\hline \multirow{2}{*}{\multicolumn{2}{|c|}{ Toplam }} & $\mathrm{n}$ & 183 & 92 & 275 \\
\hline & & $\%$ & 100.0 & 100.0 & 100.0 \\
\hline \multicolumn{3}{|c|}{ P-Değeri } & $0.4170 ̈ \mathrm{D}\left(\mathrm{LR} \chi^{2}=0.6\right.$ & & \\
\hline
\end{tabular}

öD, istatistik olarak önemli değildir ( $p>0.05)$.

Çizelge 11. Sulama durumunun üretim bölgelerine göre dağılımı ve karşılaştırma sonuçları

\begin{tabular}{|c|c|c|c|c|c|}
\hline & & & \multicolumn{3}{|c|}{ Üretim Bölgeleri } \\
\hline & & & Eski üretim bölgesi & Yeni üretim bölgesi & Toplam \\
\hline \multirow{4}{*}{ Sulama yapma } & \multirow{2}{*}{ Evet } & $\mathrm{n}$ & 3 & 10 & 13 \\
\hline & & $\%$ & 1.6 & 10.9 & 4.7 \\
\hline & \multirow{2}{*}{ Hayır } & $\mathrm{n}$ & 180 & 82 & 262 \\
\hline & & $\%$ & 98.4 & 89.1 & 95.3 \\
\hline \multirow{2}{*}{\multicolumn{2}{|c|}{ Toplam }} & $\mathrm{n}$ & 183 & 92 & 275 \\
\hline & & $\%$ & 100.0 & 100.0 & 100.0 \\
\hline
\end{tabular}

*, istatistik olarak önemlidir $(\mathrm{p}<0.05)$.

Çizelge 12. Destek alınan kurumların üretim bölgelerine göre dağılımı ve karşılaştırma sonuçları

\begin{tabular}{|c|c|c|c|c|c|}
\hline & & & \multicolumn{3}{|c|}{ Üretim Bölgeleri } \\
\hline & & & Eski üretim bölgesi & Yeni üretim bölgesi & Toplam \\
\hline \multirow{10}{*}{$\begin{array}{l}\text { Destek alınan } \\
\text { kurumlar }\end{array}$} & \multirow{2}{*}{ Tarım İl/İlçe Müdürlüğü } & $\mathrm{n}$ & 147 & 74 & 221 \\
\hline & & $\%$ & 80.3 & 80.4 & 80.4 \\
\hline & \multirow{2}{*}{ Üniversite } & $\mathrm{n}$ & 3 & 0 & 3 \\
\hline & & $\%$ & 1.6 & 0.0 & 1.1 \\
\hline & \multirow{2}{*}{ Ziraat Odası } & $\mathrm{n}$ & 2 & 3 & 5 \\
\hline & & $\%$ & 1.1 & 3.3 & 1.8 \\
\hline & \multirow{2}{*}{$\begin{array}{l}\text { Tarım İl/ilçe Müdürlüğü ve } \\
\text { Ziraat Odası }\end{array}$} & $\mathrm{n}$ & 10 & 4 & 14 \\
\hline & & $\%$ & 5.5 & 4.3 & 5.1 \\
\hline & \multirow{2}{*}{ Hiçbiri } & $\mathrm{n}$ & 21 & 11 & 32 \\
\hline & & $\%$ & 11.5 & 12.0 & 11.6 \\
\hline \multirow{2}{*}{\multicolumn{2}{|c|}{ Toplam }} & $\mathrm{n}$ & 183 & 92 & 275 \\
\hline & & $\%$ & 100.0 & 100.0 & 100.0 \\
\hline & P-Değeri & & $0.395^{\circ ̈ D}\left(L R \chi^{2}=4.07 \mathrm{C}\right.$ & & \\
\hline
\end{tabular}

öD, istatistik olarak önemli değildir ( $p>0.05$ ). 


\section{Sonuç ve Öneriler}

Bu araştırmada, Türkiye'de findık üretiminin yoğun olarak yapıldığı eski ve yeni üretim bölgelerindeki fındık yetiştiriciliği yapan işletmeler tarımsal üretim açısından karşılaştırmalı olarak analiz edilmiştir. Araştırma sonucunda, işletme yöneticisinin öğrenim durumu, ikamet yeri, fındık bahçesinin yaşı, hasat şekli, hasatta makine kullanımı ve sulama durumunun findık üretim bölgelerine göre değişim gösterdiği tespit edilmiştir. Yeni üretim bölgesindeki işletmelerde eski üretim bölgesindeki işletmelere göre eğitim seviyesinin daha yüksek olduğu ve üreticilerin daha yüksek oranda köylerde ikamet ettiği anlaşılmıştır. Eski üretim bölgesindeki işletmelerin büyük çoğunluğunun findık bahçeleri 31-60 yaș aralığında yaşlı ağaçlardan oluşurken, yeni üretim bölgesindeki işletmelerde fındık bahçeleri 030 yaş aralığındadır. Yeni üretim bölgesinde yeni fındık dikim alanlarının yüksek olduğu anlaşılmaktadır. Eski üretim bölgesindeki fındık bahçelerinin daha yaşlı ağaçlardan oluşmasının yanı sıra bölgede gerek findık hasadının yerden yapılmasının ve hasatta makine kullanımının gerekse fındık bahçelerini sulama durumunun diğer üretim bölgesine nazaran daha düşük olduğu saptanmıștır. Bu nedenle her iki üretim bölgesindeki fındık işletmelerinin de tarımsal üretimde bilgi ve uygulama konusunda bilinçlendirilmesi önemli bir ihtiyaç olarak ortaya çıkmaktadır. Aynı zamanda her iki üretim bölgesinin sosyal durumu, arazi yapısı, eğim, vs durumları da dikkate alındığında verimi yükseltme ve maliyeti düşürmeye odaklanılarak uygulamalar arasında bazı farklılıklar da ortaya çıkabilmektedir.

Üretim bölgelerinde Tarım Müdürlüklerinin yanı sıra Ziraat Odaları ve Tarım danışmanları tarafından Üniversitelerden de destek alınarak eğitim programlarına ağırlık verilmeli, konuyla ilgili STK, kooperatif veya üretici birlikleri ile gönüllü olarak uygulamaya katılacak fındık bahçesi sahipleri de öncelikli hedef grupları olmalıdır.

\section{Kaynaklar}

Aaker, D.A., Kumar,V., Day, G.S. 2007. Marketing Research, 9. Edition, John Wiley\&Sons, Danvers.

Anonim,2018a. 2017 Yılı Fındık Raporu. Gümrük ve Ticaret Bakanlığı Kooperatifçilik Genel Müdürlüğü. http://koop.gtb.gov.tr/data/5ad06bb9ddee7dd8b 423eb23/2017\%20F\%C4\%B1nd\%C4\%B1k\%20Ra poru.pdf (Erişim tarihi: 20.10.2018).

Anonim, 2018b. Türkiye İstatistik Kurumu http://www.tuik.gov.tr (Erişim tarihi: 05.10.2018).

Anonim,2018c. Findık Raporu - 2018 http://www.zmo. org.tr/genel/bizden_detay.php?kod=30070\&tipi $=1$ 7\&sube=0 (Erişim tarihi: 10.10.2018).

Cinemre, H.A. ve Kılıç. 2015. Tarım Ekonomisi, Ondokuz Mayıs Üniversitesi, Ziraat fakültesi, Ders Kitabı, No:11, (5. Baskl), Samsun.

İslam, A. 1997. Doğu Karadeniz bölgesinde Fındık Tarımı. Doğu Karadeniz Bölgesi Sosyoekonomik Sorunları Sempozyumu, Bildiriler Kitabı. 63-70

İslam, A., 2018. Hazelnut culture in Turkey. Akademik Ziraat Dergisi 7(2):259-266

Kılıç, O. 1997. Samsun İli Çarşamba ve Terme İlçelerinin Ova Köylerinde Fındık Üretimine Yer Veren Tarım İşletmelerinin Ekonomik Analizi ve Fındığa Alternatif Üretim Planlarının Araştırılması. Ankara Üniversitesi, Fen Bilimleri Enstitüsü, Tarım Ekonomisi Anabilim Dalı, Doktora Tezi, s.170, Ankara.

Kılıç, O., 2004. Türkiye'de Fındık Dikim Alanlarının Daraltılması ve Alternatif Ürün Çalışmaları (Samsun İli Örneği). 3.Milli Fındık Şürası, 10-14 Ekim 2004, Giresun, 491-494.

Kılıç, O. ve Demir, T. 2004. Türkiye'de Findık Yetiştiriciliğinin Yapısal Özellikleri, Girdi Kullanımı ve Maliyet Unsurları. 3.Milli Fındık Șürası, 10-14 Ekim 2004, Giresun, 241-244.

Kızıltan, A. ve Yalçın, H. 2010. Türkiye'de Findık Sektöründe Üreticilerin Sorunları: Samsun İlinde Bir Uygulama. Atatürk Üniversitesi İktisadi ve İdari Bilimler Dergisi, 24(4): 79-98.

Öztürk, D., Akçay, Y. 2011. "Fındık Yetiştiriciliği Yapan İşletmelerin Ekonomik Analizi (Samsun İli Çarşamba ve Terme Ovası Örneği)", Gaziosmanpaşa Üniversitesi Ziraat Fakültesi Dergisi, 28 (2):73-83

Öztürk, D., İslam, A. 2014. “Türkiye'de Organik Ürünlerin Pazarlanması", Gaziosmanpaşa Üniversitesi Sosyal Bilimler Enstitüsü, Sosyal Bilimler Araştırmaları Dergisi, 1(9): 75-94

Öztürk, D., Kasko Arıcı, Y. 2017. Fındık İșletmelerinin Üretim ve Pazarlama Sorunlarının Analizi: Samsun İli Örneği. Ordu Üniversitesi Sosyal Bilimler Araştırmaları Dergisi, 7(1): 21-34. 